\title{
EL EJERCICIO DE LA POTESTAD LEGISLATIVA DELEGADA AL PRESIDENTE DE LA REPÚBLICA ENTRE LOS AÑOS 1833 Y 2014
}

\author{
THE EXERCISE OF LEGISLATIVE AUTHORITY DELEGATED TO THE \\ PRESIDENT BETWEEN THE YEARS 1833 AND 2014
}

\begin{abstract}
Alan Bronfman Vargas ${ }^{*}$
RESUMEN: Este artículo revisa el ejercicio de la potestad legislativa delegada desde 1833 hasta el 2014. En el siglo XIX su utilización responde a autorizaciones parlamentarias de mayor extensión, que comprenden la actividad legislativa. En el siglo XX, los decretos con fuerza de ley nacen como práctica praeter constitutionem en 1927 y siguen operando como autorizaciones para regular con rango de ley y no como encargos sobre materias precisas. Su principal uso inicial entre 1927 y 1932 (control del gasto público y reorganización de la administración del Estado) se mantiene durante todo el siglo pasado. Su incorporación a la Constitución en 1970 y luego a la de 1980, intenta reforzar su carácter de encargo. Sin embargo, en la práctica, la delegación sigue funcionando como una autorización para regular con rango de ley materias de organización administrativa.
\end{abstract}

Palabras clave: Ley, delegación, potestad legislativa, potestad reglamentaria, Constitución de 1833, Constitución de 1925, Constitución de 1980.

ABSTRACT: This article reviews the exercise of legislative power delegated from the 1833 Constitution to the present. In the XIX century its use responds to broad authorizations from Congress, which include Congressional Legislative Power. In the XX century, rules of legislative force and effect were born as practice praeter constitutionem in 1927 and continue to operate as broad authorizations to regulate with the status of law and not as precise mandate. Its main initial use between 1927 and 1932 (control of public expenditure and reorganization of the public administration) is maintained throughout the past century. Its incorporation to the Constitution in 1970 and then to that of 1980, tries to reinforce its commission character. However, in practice, the delegation continues to function as an authorization to regulate matters of administrative organization with legislative force and effect.

Keywords: Act, delegation, legislative power, regulation, regulatory domains, Constitution of 1833, Constitution of 1925, Constitution of 1980.

\footnotetext{
Doctor en Derecho por la Universidad de Santiago de Compostela. Profesor de Derecho Constitucional de la Pontificia Universidad Católica de Valparaíso. Dirección postal: Avenida Brasil 2950, Valparaíso. Dirección electrónica: alan.bronfman@pucv.cl. Este artículo forma parte del proyecto de investigación Fondecyt núm. 1151365, titulado "Perspectivas para el desarrollo de la facultad de delegar la potestad legislativa en Chile en armonía con las exigencias de un régimen democrático representativo y de separación de poderes”. El autor agradece la colaboración de la profesora Mg. María Trinidad de la Maza Ovalle.
} 


\section{INTRODUCCIÓN}

El traspaso de la potestad legislativa desde el Congreso al Presidente de la República puede realizarse utilizando dos técnicas distintas. Una técnica posible consiste en que el Congreso otorga un permiso formal al Presidente de la República para crear normas generales o intervenir en asuntos cuya regulación corresponde a la ley. Otra técnica posible consiste en que el Congreso traspasa su poder legislativo al Presidente de la República para "que haga sus veces" en unos asuntos o materias determinados ${ }^{1}$. Esta segunda técnica supone un encargo preciso dirigido a la utilización de la potestad legislativa en un ámbito o materia acotado.

En este trabajo, de modo convencional, denominaremos a la primera técnica autorización y a la segunda delegación. Si bien dichos términos son utilizados como sinónimos por la regulación constitucional chilena de la delegación (art. 64 CPR), creemos que nuestra historia permite y recomienda darles un sentido diferenciado, sin que ello tenga pretensión de incidir en la interpretación del texto constitucional vigente.

Sostendremos, en las líneas que siguen, que la autorización es la técnica inicial de traspaso de la potestad legislativa en el siglo XIX en Chile y que resurge en 1927. Los encargos normativos sobre materias particulares son escasos en el siglo XX. El constituyente, en todo caso, incorpora la especificación de materias como base formal para la delegación, primero en la reforma constitucional de 1970 y luego en el texto fundamental de 1980.

La autorización es una técnica que forma parte del proceso de constitucionalización del poder de gobierno durante el siglo XIX. Tanto en Chile como en varios regímenes políticos de Europa occidental, este proceso intentó formalizar y delimitar, mediante la Constitución y la ley, los poderes del soberano que otrora sustentaron el nacimiento del Estado moderno $^{2}$. Dicho proceso tiene una relación directa con el fortalecimiento del Congreso (que autoriza pues tiene la potestad sobre la materia) y con el desarrollo de la regulación de las potestades de gobierno preexistentes.

En la etapa inicial de construcción del Estado de Chile, en la primera mitad del siglo antepasado, una idea aceptada sobre el funcionamiento de la separación de poderes, en lo que a legislación se refiere, era que al Congreso correspondía el control sobre los asuntos atingentes a la libertad del individuo y a la protección de su propiedad y que al Poder Ejecutivo pertenecían la potestades extraordinarias para enfrentar las circunstancias de excepción ${ }^{3}$. Dicho esquema inicial, por cierto, en el período de formación del Estado chileno,

\footnotetext{
1 La expresión forma parte de la definición de delegar del diccionario de la RAE.

2 En términos de Loughlin, el poder despótico declinó, sometido a restricciones institucionales que avanzaron en su racionalización. Para este autor el poder del Ejecutivo tiene dos componentes, potestas y potentia. La primera se legitima por medio del consentimiento y por ello requiere de la intervención del Congreso, y atañe al beneficio directo de sujetos particulares (derechos subjetivos y libertades). La potentia, en cambio, fundamenta su despliegue en los fines de la comunidad política, el bien supremo de pueblo, y subsiste bajo distintos nombres en el constitucionalismo, pues sus restricciones nunca han sido completas. LoUGHLIN (2012) pp. 168, 375, $376,378,383,385$ y 434 .

3 Esta idea puede reconducirse a Montesquieu, quien distinguía entre el poder ejecutivo de los asuntos que dependen del derecho de gentes y poder ejecutivo de los asuntos que dependen del derecho civil; MONTESQUIEU (1998) pp. 107, 128 y 129. En particular, al Congreso le interesaban la libertad personal, la seguridad indivi-
} 
generaba tensión y fricción entre ambos poderes, y ello explica, en parte, la inestabilidad de los períodos 1818-1830 y los problemas del gobierno de Manuel Montt ${ }^{4}$. La división inicial, sin embargo, se modifica durante el desarrollo del siglo XIX tanto por el desarrollo de legislación protectiva de la libertad, como por la continua reducción de la noción de excepcionalidad 5 .

Conviene notar que la técnica de la autorización, en la primera mitad del siglo XIX, se relacionaba más bien con el problema que requiere de una intervención estatal extraordinaria, como una guerra o insurrección, y no con el instrumento de acción estatal cuya utilización se permitía. De hecho, como explicaremos más abajo, lo que la Carta de 1833 en su art. 36 núm. 6 permitía era otorgar al Presidente de la República "facultades extraordinarias" en general y no una potestad legislativa en particular. La autorización, entonces, no se concebía como un medio para traspasar una potestad normativa reservada al Congreso, sino una herramienta para enfrentar un problema estatal de excepcional gravedad y que, eventualmente, podía requerir el uso de una potestad legislativa extraordinaria.

La delegación, en cambio, supone un estadio de desarrollo superior del orden constitucional, en que la racionalidad y la legalidad han acotado de modo significativo la discrecionalidad del poder administrativo. Algunos sostienen que dicho poder se reduce y queda confinado en potestades regulatorias que previenen daños futuros, concentradas en precaver usos lesivos de la libertad y la propiedad ${ }^{6}$. En el nuevo contexto delegatorio, el traspaso de la potestad legislativa se entiende como un encargo normativo preciso al Poder Ejecutivo, cuyo fundamento es la imposibilidad o dificultad del Congreso para realizar una tarea legislativa considerada urgente y prioritaria ${ }^{7}$.

En este trabajo revisamos la utilización de la potestad legislativa delegada desde 1833 hasta el 2014, como camino para descubrir cómo se ha concebido el traspaso de la potestad legislativa bajo las tres constituciones de mayor vigencia en Chile. Desde ya podemos afirmar que la técnica decimonónica de la autorización no ha sido reemplazada por la técnica de la delegación, concebida esta última como un encargo normativo especial dirigido a la regulación de una materia determinada fijada por el Congreso con base en una necesidad política particular. La autorización, creemos, explica bien la transferencia de la potestad legislativa en los inicios de la vigencia de la Carta de 1925, y se mantiene como criterio que hace operar la mayor parte de la legislación delegada hasta 1973. Desde 1990 en adelante,

dual y la propiedad, como también las libertades de imprenta y religión; ColLIer (1977) pp. 146-154. Para Mayer, la clásica reserva de ley establecida por las constituciones era la derivada de los derechos fundamentales con reserva expresa o tácita de las limitaciones que estas libertades pueden sufrir por la ley o en virtud de la ley; Mayer (1949) p. 98. IANCu (2012) pp. 189 y 190; EyZaguirre (1987) pp. 98, 134, 140.

4 Tensión y fricción que expresa las discrepancias entre las fuerzas políticas conservadoras y liberales. Las primeras entendían que la Constitución y la ley debían subordinarse, en determinadas circunstancias, a la necesidad del gobierno de conservar el orden público. Las segundas defendían la primacía general y permanente de la Constitución y la ley. Faúndez (2011) p. 42; Villalobos (2005) p. 123; Góngora (1994) pp. 41, 42, 45; EDWARDS (1972) pp. 62-75.

5 La aprobación del Código Civil es un claro hito en esta materia, como también la reforma constitucional de 1874. Heise (1986) pp. 150, 86.

6 IANCU (2012) p. 190.

7 Carey y Shugart (1998) pp. 2, 17. 
el traspaso de potestad legislativa sigue funcionando como una autorización para la reorganización de las plantas de la Administración del Estado, un área en que confluyen el interés del Congreso por el control sobre el gasto aprobado en la Ley de Presupuestos y la facultad de autoorganización que pertenece a cada poder.

\section{EL CONTEXTO DE LA FUNCIÓN LEGISLATIVA, EL ÁMBITO DE LA LEYY LA DELEGACIÓN LEGISLATIVA ENTRE 1833 Y 1924}

El funcionamiento de la delegación legislativa en el régimen constitucional establecido en 1833 exige conocer cómo se configuraba y cómo ejercía el Congreso Nacional su potestad legislativa. En una mirada dirigida al ejercicio poder político, la fijación de una materia como reserva de ley podía asegurar la intervención del Congreso en la decisión de que se trataba y, por lo mismo, el ámbito de la ley tenía la posibilidad de operar como un instrumento de negociación o primacía en la relación Ejecutivo-Legislativo ${ }^{8}$. Adelantemos que el Congreso, en términos generales, no intentó en este período asegurar o expandir su poder mediante el reconocimiento político, constitucional o legal del alcance excluyente de su potestad legislativa ${ }^{9}$. Bajo esta premisa, cabe distinguir al menos una fase previa a $1830 \mathrm{y}$ dos grandes etapas: $1830-1874$ y $1874-1925$.

Antes de la revolución de 1830, la Asamblea funcionaba de manera escasa e intermitente, y sus integrantes exhibieron un interés político centrado en participar en la construcción del nuevo orden institucional y constitucional ${ }^{10}$. Los intentos por levantar dicho orden imitaban las fuentes españolas, francesas o norteamericanas disponibles y no se observa el propósito de diseñar un proceso legislativo para otorgar preponderancia o ventaja a uno u otro poder ${ }^{11}$. En este sentido, la importación de reglas constitucionales se movió entre las doctrinas europeas liberales y la idea -no siempre explícita- de mantener algunas instituciones jurídicas hispánicas, sin utilizar la ley como base de una distribución competencial reservada al Congreso ${ }^{12}$. En las circunstancias políticas inestables del período, el Congreso no adoptó sus principales decisiones de gobierno por medio de leyes, ni demostró interés

\footnotetext{
${ }^{8}$ Notemos que el esfuerzo por extender el dominio de la ley se apoya desde el siglo XVIII en el propósito codificador. No fue un esfuerzo liderado por el parlamento en la mayoría de los países de Europa occidental. Los parlamentos del siglo XIX aprobaban pocas leyes y muy pocas leyes de carácter general. Pereira recuerda que hasta el segundo tercio del siglo XX el Parlamento británico legislaba poco. En el siglo XIX, la inmensa masa de leyes aprobadas en Westminster eran "especiales", aplicables solo a un caso, como en Chile en el mismo período; Bagehot (1966) pp. 153 y 154; Pereira (1992) p. 166; y Pereira (2015) pp. 323-326.

9 Bravo Lira (1992-1993) pp. 308, 311, 312, 315, 316 y 319. Sin perjuicio de su defensa de su poder normativo de control sobre el gasto y sobre el presupuesto de la administración pública.

10 Con la expresión "asamblea" aludimos a todas las asambleas del período que asumen funciones representativas, legislativas o constituyentes. VALENCIA (1986) pp. 1-109.

11 Sin perjuicio de la primacía más bien autoritaria del Ejecutivo en las Cartas de 1818 y 1822 (que también se proyecta en el proceso legislativo) y que se contrapone al liberalismo de las de 1823 y 1828; FAúNDEZ (2011) p. 31.

12 Según Edwards, no existía a comienzos del siglo XIX una base doctrinal y política que sustentase la emancipación con ideas propias; EdWARds (1959) p. 27. Heise opina de manera similar; CARRASCO (2002) p. 26.
} 
en la protección del ámbito de la ley ${ }^{13}$. Lo anterior, por cierto, excluyendo su participación en la elaboración del nuevo orden constitucional ${ }^{14}$. En este terreno, su labor representativa y legislativa se limitó más bien al reconocimiento de derechos en las distintas constituciones ${ }^{15}$. Además, como señala Barros Arana "con frecuencia se perdía el tiempo en negocios extraños a la intervención del Poder Legislativo" y alude a la "esterilidad de una asamblea", sosteniendo que otro resultado habría necesitado "de un tiempo de que el Congreso no pudo disponer" 16 .

El primer período comienza con la vigencia del texto constitucional de 1833, en el momento en que el Congreso Nacional inicia su funcionamiento regular y el cumplimiento de los mandatos de la Constitución se erige como un propósito compartido por el Presidente y las mayorías parlamentarias ${ }^{17}$.

La Constitución de 1883 configuraba cuatro ámbitos de reserva, tres de ellos de base constitucional (la formal que nacía del artículo 37; la del artículo 12; y la de otras remisiones constitucionales) y el que derivaba de la aprobación de leyes en ámbitos no reservados a ella por la Carta fundamental.

El artículo 37 reservaba ciertas materias a la ley por su importancia política o por la conveniencia de su regulación mediante disposiciones permanentes. En los doce numerales del artículo 37 no había referencias al Derecho que atañe directamente a los particulares y que compromete sus garantías fundamentales (derecho civil, penal, comercial), sino más bien a materias que, de no incluirse en el listado de asuntos de ley, perfectamente podrían ser decididas o ejecutadas por el Gobierno y la Administración sin la participación del Congreso $^{18}$. Esta reserva, entonces, aseguraba la participación del Congreso en asuntos que,

\footnotetext{
13 La categoría normativa ley fue poco utilizada en el período 1810-1830. Uno de razones es que ella se asociaba a la plena legitimidad representativa del Congreso Nacional, lo que exigía un cierto grado de control territorial en la república. Los actos normativos generales del período reciben distintas denominaciones y procedimientos: reglamentos (en su mayoría, aprobados por el Congreso a propuesta del Poder Ejecutivo), ordenanzas, bandos, acuerdos, dictámenes, oficios, senado consultos, etcétera. En casi la totalidad de los casos, el origen del cuerpo normativo es externo al Congreso. Antes de 1823 no se encuentran leyes, al menos, aprobadas bajo dicha denominación por el Congreso Nacional y entre 1823 y 1830 es posible contabilizar menos de veinte leyes. En los años 1826-1827 y 1828-1829 sí hay períodos de trabajo legislativo regular, aunque incipiente. BARROS Arana (2005) passim; Bravo Lira (1992-1993) p. 311; Letelier (1887) p. 37; Diario Oficial y Contraloría General de la República (2010) pp. 1-48.

14 En las "leyes fundamentales", como las denominó Camilo Henríquez el día de apertura del Congreso en 1811. La elaboración de las sucesivas leyes fundamentales comprometió una buena porción del limitado tiempo de sesiones. Bravo Lira (1992-1993) p. 306.

15 De todos modos, las asambleas sí participaron en la creación de normas de carácter general elaboradas y propuestas por el Poder Ejecutivo (sobre organización administrativa y judicial, procedimiento civil, derecho penal, tributos, libertad de imprenta, salarios de servidores públicos, fomento económico, aduanas, testamentos, minería, protección de indios, entre otras).

16 Barros Arana (2005) pp. 118, 271 y 272. La primera oración se refiere al Congreso de 1826 y la última al de 1828.

17 Edwards (1972) pp. 16 y 123.

18 Su antecesora sí la tenía. La Constitución de 1828, en su art. 46, referido a las atribuciones exclusivas del Congreso, disponía: "[h] acer leyes jenerales en todo lo relativo a la (...); protección de todos los derechos individuales enumerados en el capítulo tercero de esta Constitución (...)”. Ninguno de los tres proyectos que precedieron a la Carta de 1833 contiene una disposición similar.
} 
si nada se dijese, podrían pertenecer al Poder Ejecutivo según los criterios generales de la doctrina de la separación de poderes ${ }^{19}$.

Por otra parte, la Constitución contenía una reserva legal extensa (y extensible) en su artículo 12, que regulaba los derechos constitucionales. Así, el mero establecimiento de libertades y del derecho de propiedad por la Constitución, restringía el actuar del Gobierno, bien de modo absoluto (como prohibición), bien imponiéndole el deber de intervenir mediante acto legislativo. Esta reserva no estaba formulada con un mandato general, pero como fue evidente para los protagonistas del período, otorgaba sustento constitucional, político y jurídico, a las leyes de mayor relevancia social del siglo XIX ${ }^{20}$.

Al listado de materias reservadas a la ley por el artículo 37 y a las que podían deducirse del artículo 12 de la Constitución 1833, correspondía sumar las que nacían de otras remisiones constitucionales expresas ${ }^{21}$.

Por último, deben sumarse como materias reservadas a la ley las que nacían de la regulación legal creada fuera del ámbito reservado a ella por la Constitución. Estas resultaban de la aprobación de leyes que tendían a convertir lo regulado por ellas en materia de ley ${ }^{22}$.

Una vez instaurado el régimen constitucional de 1833 y fijado el ámbito de la ley, podemos observar la labor legislativa del período. A partir de 1834 comienzan a aprobarse un número importante de leyes, pero la regularidad en su trámite y aprobación solo se constata después de $1840^{23}$. La ley era, en mayor medida, la herramienta que los parlamentarios utilizaban para intervenir en decisiones de gobierno en asuntos de su interés, lo que incluía numerosas materias que en el presente se considerarían propias de gobierno o administración ${ }^{24}$. Si excluimos las leyes que atañen a la organización del aparato estatal, son pocos los cuerpos legales dedicados a la regulación general de asuntos relevantes para toda la sociedad. Como explicaremos más adelante, parte importante de dichas leyes generales tuvieron su origen fuera del hemiciclo parlamentario.

\footnotetext{
19 Es más, algunos de sus numerales admiten una interpretación claramente invasiva del campo reglamentario.

20 Carrasco decía que "(...) porque hai instituciones protectoras que velan por nosotros, porque tenemos representantes que atiendan nuestros intereses, porque es menester una espresión de la voluntad soberana, una lei, para la adopción de algunas de esas medidas, para la resolución soberana sobre esos intereses"; CARRASCO Albano (1874) p. 84. Huneeus decía que la autoridad presidencial no podía "limitar las garantías individuales, ni ofender derechos fuera de los casos expresamente previstos en la misma Constitución o las leyes"; HunEEUS (1891) pp. 39 y 9.

21 Como, entre otras, las elecciones, la inversión de rentas públicas, los departamentos ministeriales, el número de alcaldes y regidores, el gobierno interior, los pagos autorizados, las milicias, la vinculación de la propiedad, el plan general de educación pública y un conjunto de garantías fuera del art. 12. Cada reserva se configuraba con su propia extensión.

22 "Tendían" ya que determinados tipos de leyes (en especial las de nombramiento o las que otorgaban algún beneficio particular), no generaban una reserva legal sobre todas las materias o asuntos similares.

23 Entre 1831 y 1839 pueden contabilizarse un poco más de cien leyes, la mayoría de carácter particular. Hay gran oscilación en la producción legislativa anual. En los años 1830, 1838 y 1839 se aprueba solo una ley y en tres años $(1831,1833$ y 1836) el promedio anual de leyes es ocho y fracción. En los años 1832 y 1835 se aprueban cerca de veinte por año, y en 1834 cuarenta. El promedio anual en la década siguiente alcanza 28 leyes aprobadas, con una variación ostensiblemente menor.

24 El Congreso Nacional era el poder normativo más fuerte y contaba con un poder regulatorio que, en los hechos, podía menoscabar incluso la vigencia efectiva de la propia Constitución. Huneeus (1890) pp. 252 y 253 ; LASTARRIA (1906) p. 473.
} 
Aunque la institución parlamentaria creció y se desarrolló en este período, no fue la ley el principal camino escogido por los parlamentarios para proteger los derechos e intereses de sus representados, sino más bien su participación en asuntos de gobierno y administración. Es más, incluso en cuestiones importantes como la regulación y protección del derecho de propiedad, el Congreso no puede exhibir obra legislativa propia de relevancia ${ }^{25}$.

Con todo, hay dos ámbitos asociados a la función legislativa en que el Congreso sí estuvo interesado en ganar terreno al Poder Ejecutivo. El primero fue el control sobre el gasto público y, el segundo, el control sobre las decisiones gubernamentales adoptadas con poderes extraordinarios (las que hasta 1874 comprendieron facultades legislativas extraordinarias para el Presidente de la República). En ambos casos, el nacimiento de partidos políticos, apoyado por la paulatina institucionalización del Congreso, propició la participación de los parlamentarios en la decisión sustantiva por medio de la le ${ }^{26}$. En esta función, ella fue el instrumento formal que sirvió de vehículo para dicha participación política y no una herramienta regulatoria en un sentido más general.

En relación con el control del gasto, ya en el octavo año de vigencia de la Constitución se plantearon iniciativas parlamentarias para detener la tramitación de la ley de contribuciones y presupuestos con el propósito de obtener decisiones políticas del Presidente no atingentes a dichos temas ${ }^{27}$. Hacia 1861, una vez concluido el período conservador, la participación del Congreso en la designación y remoción de ministros era conocida y aceptada, y por lo mismo, el interés político sobre la ley de presupuestos comienza a ser la decisión sobre el gasto mismo y no su valor como instrumento general de negociación política ${ }^{28}$.

El Congreso también fue activo en la defensa de su potestad en materia de poderes extraordinarios presidenciales. Esta cuestión cruza la historia política chilena y, en el período 1833-1874, conserva cierta inercia del conflicto Ejecutivo-Legislativo previo a 1830. Para los parlamentarios era importante controlar las facultades extraordinarias del Presidente, en especial porque eran utilizadas contra sus adversarios políticos ${ }^{29}$. Su empleo en actos legislativos era, simplemente, una de sus expresiones, y el interés del Ejecutivo en su uso fue más bien el control de la oposición y sus motines, y no la generación de normas jurídicas permanentes ${ }^{30}$.

\footnotetext{
25 Para Locke, el poder político es, precisamente, el poder de dictar leyes para regular y preservar la propiedad. Locke (1769) p. 195. La ley del 14 de julio de 1852, el Código Civil y el Reglamento del registro del Conservador de Bienes Raíces fueron cuerpos normativos redactados fuera del Congreso, sin perjuicio que la ley y el Código fueron aprobados en sede parlamentaria. La abolición del mayorazgo, un tópico sensible para los parlamentarios, avanzó más por iniciativas del Poder Ejecutivo y normas constitucionales, que por decisiones legislativas (con excepción de la ley citada, que fue redactada por Bello). Barros Arana (2005) pp. 65, 198; EYZAGUiRRE (1986) p. 112.

26 Obando (2014) pp. 635-638.

27 En 1841 a indicación de Mariano Egaña para que el presidente Bulnes incluyese dos proyectos de ley en la convocatoria a legislatura extraordinaria. En 1857 en propósito era cambiar a ministros del gabinete. También hubo iniciativas en 1850 y 1859. EyZAGUirRe (1986) p. 108; Faúndez (2011) pp. 55.

28 Bravo Lira (1996) pp. 102-106, 208; Urzúa (1992) pp. 172-173.

29 Las facultades extraordinarias se utilizaron en 1833-1834, 1836-1837, 1838-1839, 1851-1853, 1859-1861.

Hubo estado de sitio en 1837, 1840, 1846 y 1858; Bravo Lira (1996) p. 300. UrzÚa (1992) pp. 75-77.

30 Sin perjuicio de su empleo coyuntural por parte de Mariano Egaña, cuyo fruto son sus conocidas leyes.
} 
El período que sigue se inicia con las reformas constitucionales de 1874. Estas reformas son el resultado final del paulatino estrechamiento de las potestades extraconstitucionales reconocidas al Presidente de la República. El intervencionismo presidencial en las elecciones parlamentarias fue reemplazado por el intervencionismo de los partidos políticos, los que desde una posición robustecida impusieron nuevas condiciones para el funcionamiento del régimen político y constitucional.

Las reformas constitucionales robustecieron la potestad legislativa del Congreso Nacional en cinco materias: reducción del quórum para celebrar sesiones, la inclusión de seis consejeros elegidos por el Congreso en el Consejo de Estado, la convocatoria a sesiones extraordinarias, la simplificación del proceso de insistencia de ambas cámaras (después del rechazo de la observaciones presidenciales) y la reforma del art. 36 numeral $6^{31}$. Esta última reforma modificó la norma que, en su oportunidad, sirvió para fundar la potestad legislativa extraordinaria ${ }^{32}$.

En el período 1874-1924, el predominio político de los partidos, ejercido a través del Congreso Nacional, consolidó a la ley como un instrumento decisional ilimitado en su extensión sustantiva ${ }^{33}$. En la práctica, la reserva de ley en la Constitución de 1833 operó de acuerdo a las condiciones e intereses de la política chilena del siglo XIX, sin constituir un ámbito en que el Congreso necesitase defenderse del Poder Ejecutivo.

\subsection{El ejercicio de potestades legislativas DELEGAdAS EN El RÉGIMEN CONSTITU-} CIONAL DE 1833

Como sostuvimos antes, la distribución de poderes normativos entre Presidente y Congreso en el siglo XIX no estuvo en el centro del debate político, ni en el meollo de los conflictos entre ambos poderes. En este contexto, la delegación de la potestad legislativa ocupa una posición lateral en la historia del proceso legislativo bajo la Carta de 1833. Ella surgió como resultado de una interpretación presidencial extensa de las facultades extraordinarias previstas de modo genérico por la Constitución, formulada ante un Congreso Nacional que no se opuso a dicha interpretación ${ }^{34}$. Esta forma de interpretar las facultades extraordinarias da cuenta del proceso de asentamiento del gobierno conservador, marcada por rebeliones y motines. Para terminar con esta interpretación, en el ocaso del predominio de sus sostenedores, fue necesaria la reforma 1874, antes indicada.

Entre 1833 y 1861 se aprobaron un total de seis leyes que otorgaban facultades extraordinarias al Presidente y que, por lo tanto, podían operar como leyes de autorización

\footnotetext{
31 Las dos primeras siguen a la introducción de la prohibición de reelección presidencial inmediata, de septiembre 25 de 1873 y octubre 24 de 1874 , respectivamente. Las dos siguientes son de 12 de diciembre de 1891 y 26 de junio de 1893. La última es de octubre de 1874 .

32 La modificación reemplazó la autorización al Presidente para el uso de facultades extraordinarias por el poder del Congreso para "dictar leyes excepcionales" y transitorias, limitativas de la libertad personal, de imprenta o reunión.

33 La definición del artículo $1^{\circ}$ Código Civil da cuenta de esta valoración. Claro Solar reconocía que la ley debía ser constitucional, pero "de esta constitucionalidad solo es juez el legislador mismo"; Claro Solar (1898) p. 30.

34 Esta facultad no se explicitó en ninguna de las leyes de facultades extraordinarias aprobadas, pese a que la Constitución exigía detallar expresamente las facultades concedidas.
} 
para el ejercicio de la potestad legislativa. De estas, tres se aprobaron antes de 1839, en tanto las tres restantes entre 1851 y $1861^{35}$.

De todas, la de mayor importancia fue la ley de facultades extraordinarias del 31 de enero de 1837, que autorizó al Presidente a utilizar "todo el Poder Público que su prudencia hallare necesario para regir el Estado". Ella dio lugar a sesenta y ocho decretos que las invocaban como fundamento, número que incluye un porcentaje menor de leyes en sentido material ${ }^{36}$. Las restantes cinco leyes de facultades extraordinarias permitieron adoptar un número limitado de decisiones reservadas a la ley, las que no incluyeron leyes de carácter permanente y general.

Como dijimos antes, el traspaso de potestad legislativa como parte de un haz de poderes extraordinarios generó conflicto en tanto instrumento de persecución política y, en muy menor medida, por su incidencia en la creación de normas generales y permanentes de derecho común. Destaca aquí en especial el conflicto suscitado como consecuencia de la creación de tribunales especiales en uso de facultades extraordinarias conferidas al Presidente de la República por citada ley de $1837^{37}$.

Dejando de lado el debate político, conviene observar dos cuestiones en relación con la no utilización de la delegación de la potestad legislativa. La primera es que, después de la independencia, era reconocida la necesidad de avanzar en la transformación del ordenamiento jurídico hispánico en un ordenamiento jurídico chileno y que ella solo podía atenderse con la aprobación de nuevas leyes. Pese a que nuestro naciente Congreso no tenía capacidad, herramientas, ni tradición para elaborar los cuerpos legales que reemplazasen la regulación hispana, no se consideró la posibilidad de delegar poder legislativo al Presidente ${ }^{38}$.

Por otro lado, para enfrentar el problema, hubo varias mociones que proponían encomendar a un letrado externo la codificación nacional ${ }^{39}$. En los hechos, normas relevantes para la construcción del ordenamiento legal chileno tuvieron su origen fuera del hemiciclo. Las leyes marianas fueron un esfuerzo por crear una regulación procesal nacional sin contar con consenso parlamentario directo. Con posterioridad, y luego de varios intentos frustrados, la tarea de elaborar un Código Civil fue realizada fuera del Congreso y lo mismo otros

\footnotetext{
35 1833, 1836, 1837, 1851, 1852, 1859. BRONFMAN (2017) pp. 279-281, 286-287.

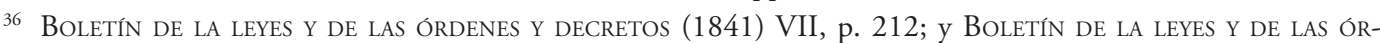
DENES Y DECRETOS (1841) VIII, pp. 10, 91 y 177. Los decretos que con mayor propiedad pueden considerarse legislativos son los referidos a materias jurisdiccionales. Su origen es un proyecto de código procesal civil redactado por Mariano Egaña.

37 El Presidente no solo creó tribunales, también aprobó normas penales. La ley de 1837 fue muy criticada. Huneeus y Roldán opinaron que ella hizo que el Congreso desapareciese de Chile entre 1837 y 1839 , lo que en materia legislativa es evidente. RoldÁn (1917) p. 338; HuneEus (1890) p. 177.

38 No obstante, sí hubo encargos al Presidente para la dictación de normas como el reglamento de Aduanas o un reglamento con fuerza de ley para fijar los deberes de amos y criados; BRONFMAN (2017) pp. 276 y 277.

39 En 1826 hubo una moción del diputado Muñoz Bezanilla en este sentido y a comienzos de la década de los treinta, dos oficios enviados por el Gobierno al Senado propusieron autorizar a un individuo para elaborar un código de leyes comprensivo de los principales ramos administrativos y de la organización económica. En 1835 el ministro del Interior propuso un proceso de codificación parcial mediante este método; Barros AranA (2005) p. 65; GuZMán Brito (1988) pp. 73-81; BraVo Lira (1983) pp. 192-197.
} 
códigos del período. A estos cuerpos legales que crean el Derecho chileno, se pueden añadir aquellos que, según la doctrina, fueron fruto de una autorización o delegación legislativa, como el reglamento del registro del Conservador de Bienes Raíces ${ }^{40}$.

Una segunda cuestión fue la relativa libertad del Presidente entre 1833 y 1860 para redactar y aprobar normas generales en materias de su interés, con prescindencia del Congreso Nacional ${ }^{41}$. El Congreso aceptaba el poder normativo de un Presidente que intervenía en la elección de los propios parlamentarios, aun cuando contaba con argumentos constitucionales para impedirlo. Al término del decenio de Montt, no obstante, dicha aceptación cambia de cariz, pues el poder de los partidos políticos alcanzaba a la presidencia de la república y no era necesario disputar la potestad normativa entre un Presidente y un Congreso sometidos a los partidos más fuertes.

Ya iniciado el proceso de debilitamiento relativo de la magistratura presidencial, esporádicamente se cuestionó el alcance del poder reglamentario del Presidente, en especial por la creación de cargos u organismos vía decreto ${ }^{42}$. Sin embargo la aprobación de los gastos permitía al Congreso validar o rechazar la creación de oficinas públicas realizada por decreto ${ }^{43}$.

En una mirada general, el acomodo de la potestad legislativa y la reglamentaria de acuerdo a los intereses del Presidente de la República y el Congreso Nacional, explica la ausencia de una necesidad imperiosa de delegar la potestad legislativa en el siglo XIX. Este acomodo, que puede comprobarse en numerosas leyes "reglamentarias" y decretos "con contenido de ley", no enfrentó ningún tipo de control jurídico externo ${ }^{44}$. Al no existir potestades de control de constitucionalidad ajenas al Poder Legislativo y Ejecutivo, ambos podían utilizar sus potestades de acuerdo a sus intereses y a lo aceptado en el juego político.

En los términos explicados, la delegación de la potestad legislativa fue más bien una autorización excepcional al Poder Ejecutivo, que formaba parte de un haz más grande de atribuciones extraordinarias, y que fue posible utilizar hasta 1860 . El predominio liberal y el robustecimiento del Congreso Nacional hicieron muy difícil su utilización después.

\section{EL ÁMBITO DE LA LEYY LA DELEGACIÓN LEGISLATIVA EN EL RÉGIMEN DE LA CONSTITUCIÓN DE 1925}

En el diseño constitucional del ámbito reservado a la ley, el constituyente de 1925 mantuvo los criterios del orden constitucional precedente. Esto es, se fijó el listado de materias que debían ser reguladas o aprobadas por ley, las que, en sus líneas centrales, conser-

\footnotetext{
${ }^{40}$ El art. 606 del Código Civil constituiría un ejemplo de delegación de potestad legislativa. No es posible esclarecer hasta qué punto esta interpretación era aceptada en el Congreso. La remisión se repite después en el Código de Comercio. El Tribunal Constitucional validó esta interpretación el año 2006 (STC 511/06).

${ }^{41}$ Que se manifiesta en especial en normas aduaneras y tributarias. El Presidente se arrogó facultades legislativas y los respectivos Congresos se manifestaron poco celosos de sus atribuciones; LeTELIER (1917) p. 489; HunEeus (1891) p. 49.

42 HeIse (1986) p. 25.

43 Letelier (1917) p. 484.

44 Aunque frente a un decreto invasor del campo legal podía reclamarse ante los tribunales, ello no sucedió.
} 
vaban los mandatos de 1833 , sin perjuicio de los cambios en materia de gasto público ${ }^{45}$. A este listado, como en 1833 , se sumaban las remisiones explícitas a la ley y las que se deducían de las garantías y libertades protegidas por la Constitución. Asimismo, completaban la reserva, por aplicación de las reglas del sistema de fuentes, todas las materias que ya fueron objeto de regulación legal.

Pese a que la idea de permitir la delegación de facultades legislativas fue rechazada en la Subcomisión que redactó el texto de 1925, en enero de 1927 se aprobó una ley que otorgaba facultades legislativas al Presidente de la República ${ }^{46}$. Entre 1927 y 1970, la delegación de la potestad legislativa funcionó como una práctica admitida y validada por los operadores del sistema político y jurídico, pese al juicio que representaba su inconstitucionalidad ${ }^{47}$.

En enero de 1970, se incorporó a la Constitución el procedimiento de delegación legislativa, tomando como base la propuesta de Jorge Alessandri de julio de $1964^{48}$. La norma recogió la experiencia de la delegación 1927 y detalló las materias en que era posible autorizar al Presidente de la República para legislar, así como las restricciones y facultades del Congreso en ejercicio de su potestad delegatoria ${ }^{49}$. El claro propósito de la reforma fue limitar el ámbito de la delegación de potestad legislativa ${ }^{50}$.

45 En materia de gasto público, los cuatro numerales de 1833 se transforman en seis numerales. Después de 1891 la nueva regulación constitucional es más detallada en lo que concierne a la ley de presupuestos.

46 Ley No 4.113. Subcomisión de Reformas Constitucionales (1925) pp. 395, 502.

47 "Delegatas potestas non delegatur" dice un conocido aforismo. En lo político, destacamos la crítica de Arturo Alessandri Palma y, en la doctrina, las de Jara, Silva Bascunán, Andrade y Estévez. La Corte Suprema, en 1932, 1933 y 1953, sostuvo que carecía de facultad para pronunciarse acerca de la potestad para delegar que se atribuía el Congreso. El 2008 el Tribunal Constitucional reconoció los DFL dictados con anterioridad a 1970, mientras no lesionasen derechos fundamentales, por los perjuicios al sistema jurídico y a la paz social que conllevaría negar dicho reconocimiento (STC 1191/08); JARA (1948) pp. 41 y 42; SiLVA BASCUÑÁn (1963) pp. 155, 163, 442; Andrade (1971) pp. 55-58; Estévez (1949) p. 239. Bernaschina, en cambio, validaba la delegación; BERNASCHINA (1958) pp. 69-73.

48 Antes de la Ley No 17.284 de reforma constitucional, hay proyectos de Eduardo Frei Montalva, Héctor Correa Letelier y Francisco Bulnes Sanfuentes y una comisión consultiva de 1954 creada por Ibáñez para el tema. El proyecto de reforma constitucional de julio de 1964, redactado por Enrique Ortúzar y Enrique Silva Cimma, tiene algunas diferencias con el aprobado en 1970; Evans (1970) pp. 113-114, Cordero (2010) p. 56.

49 El nuevo numeral $15^{\circ}$ del art. 44 permitía dictar DFL en materias tales como: creación y organización de los servicios del Estado y de las Municipalidades; fijación de plantas y de regímenes previsionales del sector público; creación de contribuciones; contratación de empréstitos; enajenación de bienes del Estado o de las Municipalidades. Los prohibía para la regulación de la nacionalidad, ciudadanía, elecciones, plebiscitos y materias comprendidas en las garantías constitucionales (salvo la admisión en empleos y funciones públicas; el modo de usar, gozar y disponer de la propiedad, y sus limitaciones y obligaciones; la protección al trabajo, a la industria y a las obras de previsión social). Tampoco podían regular la organización, atribuciones y régimen de los funcionarios del Congreso Nacional, Poder Judicial y Contraloría General de la República, ni exceder un año. El Congreso debía señalar en la ley autorizatoria las "materias precisas" de la delegación, pudiendo agregar limitaciones, restricciones y formalidades. Estas últimas no eran mencionadas en el proyecto de julio de 1964.

50 Silva Cimma señalaba que la ley que autorizaba el DFL debía ser específica y que, "en el evento de dudas, debe concluirse que la delegación de atribuciones no fue dada”; Silva Cimma (2008) p. 105. Guzmán Dinator sostiene que la reforma de 1970 impidió delegar materias que implican el ejercicio de funciones políticas; CENC (1977) p. 306. En las discusiones del Consejo de Estado sobre el proyecto de Constitución de 1980, Jorge Alessandri cuestionaba la amplitud de la delegación y su uso histórico para "caracterizar la administración pública" y "reemplazar numerosos empleados por otros" que gozan del favor de los partidos mayoritarios. El 
Como dijimos arriba, la necesidad de delegar la potestad legislativa tiene una relación directa con el control de constitucionalidad y su funcionamiento. Tal control puede limitar el poder de decisión de los órganos políticos en lo referido a la extensión de las competencias legislativa y reglamentaria y, eventualmente, forzar la delegación de la potestad legislativa o hacerla innecesaria.

En este sentido, la creación de la Contraloría General de la República en el año 1927 (y su constitucionalización en 1943) y del Tribunal Constitucional en 1970, sin duda, mermaron la capacidad de los poderes políticos para distribuir y ejercer la potestad normativa general de acuerdo con sus intereses ${ }^{51}$. Con todo y sin perjuicio que la destitución del contralor Agustín Vigorena en 1945 puso de manifiesto el interés del Congreso en controlar algunos aspectos de la actividad normativa presidencial, lo cierto es que hasta la década de 1960, el control sobre la constitucionalidad y legalidad de los decretos presidenciales estuvo subordinado al interés de los partidos políticos dominantes en el Congreso ${ }^{52}$. Tales partidos, en los hechos, estaban más interesados en obtener cargos en el gabinete que en limitar un poder presidencial que podía ser útil a su agenda política ${ }^{53}$. En la década de los sesenta, el Presidente, paulatinamente, fue perdiendo la confianza de unos partidos predominantes nuevos, los que defienden un escrutinio más intenso sobre un ejercicio de potestades normativas que podría ser contrario a sus intereses.

\subsection{El ejercicio de la potestad legislativa delegada en el Régimen CONSTitu- CIONAL DE 1925}

La revisión del ejercicio de la potestad legislativa delegada desde 1925 puede organizarse en cuatro grandes períodos: inicial (1927-1931), de desarrollo (1931-1970), constitucional (1970-1973), y provisorio (1973-1980).

En el primer período, Ibáñez introduce la delegación del poder legislativo como medio para avanzar en su programa de gobierno, en un momento de incertidumbre y cambios políticos significativos. No había norma constitucional habilitante y, por lo mismo, la legitimidad jurídica de los DFL fue precaria, pero se afianzó con éxito tanto por el consenso político que los amparó como por razones prácticas. La razón ex post de mayor peso -que también sirvió para justificar más de ochocientos decretos leyes dictados entre 1924 y 1925-, fue que dejar sin efecto las normas vigentes podría causar un daño más grave al ordenamiento jurídico que tolerar su validez.

En el segundo período (1931 a 1970), los DFL se consolidan como práctica extra constitucional y se utilizan con mayor o menor frecuencia, siempre en materias convenientes para los intereses del Congreso, dependiendo de los apoyos parlamentarios del Presidente obtenidos gracias a cargos en el gabinete.

proyecto del Consejo de Estado enumeró las materias delegables, propuesta que fue desechada por la Junta de Gobierno, que volvió al proyecto CENC; CE (1979), sesión 88, pp. 1-2 y 89.

51 El Tribunal Constitucional por sentencia del 5 de abril de 1972 (Rol 5/72), declaró inconstitucional un DFL que estimó dictado fuera del plazo autorizado por la ley delegatoria, aprobada el 25 de julio de 1970.

52 FAúndez (2011) pp. 133 y 143.

53 FAúndeZ (2011) pp. 125-127, 149, 151 y 268. 
En el tercer período (1970-1973), la delegación legislativa fue regulada por la Constitución de 1925, pero el Presidente careció de apoyo en el Congreso y casi no pudo utilizarla.

En el cuarto período (1973-1980), la concentración de poder y la vigencia parcial de la Constitución de 1925, no desincentivaron su utilización por parte del gobierno militar.

\subsection{Período 1927-1931}

En enero de 1927 se publicó la primera ley delegatoria, la Ley No 4.113, la que de un modo un tanto ambiguo, facultaba al Presidente a dictar normas que podrían tener incidencia sobre disposiciones de rango legal ${ }^{54}$. Esta ley fue seguida por otras seis que delegaron potestad legislativa, la última de las cuales fue la Ley No 4.795 de febrero de 1930. Estas leyes beneficiaron al proyecto político del presidente Ibáñez y ampararon un total de setecientos cuarenta y tres DFL, número similar al de leyes dictadas en el mismo período ${ }^{55}$. En promedio se dictaron más de cien DFL por cada ley delegatoria.

De las siete leyes delegatorias, cuatro contienen mandatos referidos a materias y tres son autorizaciones generales ${ }^{56}$. Dentro de las últimas, la Ley No 4.945, autorizaba al Presidente "para dictar todas las disposiciones legales de carácter administrativo o económico que exija la buena marcha del Estado" ${ }^{57}$. Por lo dicho, no es posible asociar la técnica delegatoria a un encargo parlamentario dirigido a la reforma del ordenamiento jurídico en determinadas y precisas materias, sino más bien corresponde entenderla como una autorización parlamentaria para abordar asuntos de interés para el Poder Ejecutivo con normas con rango de ley. Tales autorizaciones amplias fueron expresión de una voluntad política mayoritaria que apoyaba al Presidente en su propósito de reorganizar la Administración Pública y ordenar el gasto fiscal, en línea con las propuestas de la misión Kemmerer.

\subsection{PeríODO 1931-1970}

La delegación de la potestad legislativa en este período y su utilización exhiben importantes diferencias cualitativas y cuantitativas dependiendo del mandato presidencial de que se trate ${ }^{58}$. Los presidentes Arturo Alessandri, Pedro Aguirre Cerda, Juan Antonio Ríos y Gabriel González Videla, no contaron con leyes delegatorias o bien las utilizaron con poca

\footnotetext{
${ }^{54}$ Esta ley autorizaba al Presidente a utilizar la declaración de vacancia de cargos previstos en la ley. El Presidente, sin esta autorización, de todos modos podría haber realizado tal declaración en uso de su potestad de administración, pero sin la Ley No 4.113 de por medio, el Congreso habría podido cuestionar el socavamiento de su autoridad legislativa.

55850 leyes se dictaron en este mismo período. El período de aprobación de normas con rango de ley más intenso precede a Ibáñez. Son los años 1924 y 1925 en que se aprueban 809 decretos leyes y 65 leyes.

56 De las cuatro referidas a materias en particular, tres son sobre educación y una autoriza la dictación del Estatuto Administrativo y la regulación de la incorporación de Arica al régimen político y administrativo del país.

57 Silva Cimma sostiene que todos los presidentes solicitaban la potestad legislativa delegada invocando razones administrativas y económicas; Silva Cimma (2008) p. 104.

58 Las leyes delegatorias suman más de 25 y los DFL dictados un número que oscila, según distintas fuentes (base de datos de la BCN, de la CGR y del Diario Oficial), entre 650 y 1500. La diferencia estriba en la inclusión o exclusión de más de 400 decretos de 1968, que implementan la reforma agraria.
} 
frecuencia ${ }^{59}$. En cambio los presidentes Carlos Ibáñez, Jorge Alessandri y Eduardo Frei obtuvieron leyes delegatorias y las utilizaron en decretos que representan cerca del $90 \%$ del total de DFL dictados en el período ${ }^{60}$. Estas diferencias, por cierto, se relacionan con la fuerza de las bancadas parlamentarias que apoyan al Presidente y sus principales intereses (los que incluyen no legislar desde el hemiciclo), pero también con el poder negociador del Poder Ejecutivo y el respaldo partidista y social a los programas políticos y legislativos de cada Presidente. Notemos que dos de los presidentes que dictan mayor número de DFL de ley en esta etapa, Jorge Alessandri y Carlos Ibáñez, carecían de un apoyo partidista propio y fuerte en el Congreso Nacional. Es probable que la suma de la mejor información disponible para el Presidente, los problemas de la negociación partidista en las cámaras y la imposibilidad de lesionar los principales intereses legislativos de los parlamentarios mediante DFL, haya incidido en la decisión política de delegar la potestad legislativa ${ }^{61}$.

En relación con las materias reguladas por los decretos legislativos, priman las referidas a la reorganización de la Administración Pública en directa relación con el propósito de contener el gasto público y con objetivos económicos tributarios o de control sobre el mercado y los precios ${ }^{62}$. Otra materia administrativa que fue objeto de un buen número de DFL fue la creación de nuevos órganos del Estado ${ }^{63}$. En el discurso político, la contención del gasto en personal tenía una relación directa con el freno al clientelismo, la inflación y la creciente carga fiscal derivada de los salarios públicos y, por ello, su debate en el Congreso no tenía grandes defensores ${ }^{64}$. En lo administrativo, además, merecen mención el estatuto administrativo y la ley orgánica de presupuesto.

\footnotetext{
59 Arturo Alessandri no solicitó delegación de la potestad legislativa pues propuso su inclusión en el texto de 1925 y fue rechazada. Aguirre Cerda no recibió delegación de potestad legislativa. Ríos la tuvo en tres leyes delegatorias, las que fundaron $10 \mathrm{DFL}$, e impulsó la reforma constitucional que incorporó a la iniciativa exclusiva para la creación de nuevos servicios públicos y empleos rentados. González Videla solo dictó 5 DFL. SILVA BASCUÑÁN (1963) p. 160.

${ }^{60}$ En el segundo período de Ibáñez, se aprueban, según la BCN, 205 DFL (la base de datos de la CGR señala que son 422 DFL - 400 en 1953- y la compilación del Diario Oficial citada en la bibliografía reduce este número a 201). Jorge Alessandri habría dictado 224 DFL en su período (1022 según la CGR), buena parte de los cuales se concentran en el año 1960 (700 según la CGR y 160 según la BCN). El presidente Frei Montalva, por último, aprueba 99 DFL (698 según la CGR).

61 Carey y Shugart (1998) pp. 296 y 297.

62 En el ámbito tributario las normas delegadas, por lo común, fijan criterios de aplicación o establecen exenciones.

63 Algunos por fusión de entidades preexistentes. Se crean o reorganizan, por ejemplo, en 1953, el Ministerio de Minas, la Empresa de Transportes Colectivos del Estado, la Superintendencia de Educación Pública, el Banco del Estado, el Instituto de Seguros del Estado, la Superintendencia de Seguridad Social, la Empresa Marítima del Estado; en 1956, el Consejo de Defensa del Estado; en 1959, el Ministerio de Trabajo y Previsión Social y el de Salud; y en 1960, la Empresa Nacional de Minería, el Consejo Superior de Seguridad Nacional y la Junta de Comandantes en Jefe, Astilleros y Maestranzas de la Armada, y la Empresa Portuaria; Urzúa (1970) pp. 179-198.

${ }^{64}$ Con todo, las cifras no exhiben resultados significativos en este propósito. El sector centralizado del funcionariado se incrementó de modo constante desde 1935. En 1950 se estimaba que el número total de funcionarios estatales superaba los 200.000. Los DFL, parece, no ayudaban a solucionar el problema. URZúA y GARCía (1971) pp. 74, 75, 80.
} 
El listado de los restantes contenidos no es muy extenso ${ }^{65}$. En sus efectos sociales destacan los DFL que regulan las rentas de arrendamiento de inmuebles, salario mínimo para obreros agrícolas y asignación familiar para obreros. Son pocos los DFL destinados a fijar textos refundidos en este período ${ }^{66}$.

En relación con las leyes delegatorias, desde 1942, su tenor tiende a "precisar con mayor acuciosidad las bases dentro de las cuales se otorga cada una de las autorizaciones que se confieren al Presidente de la República” ${ }^{67}$. De todos modos, los números en su conjunto indican que, en promedio, cada ley delegatoria sirvió de base a lo menos treinta decretos con fuerza de ley.

\subsection{PERÍODO 1970-1973}

Este período tiene como notas distintivas la aprobación de la reforma de 1970, que incorpora los DFL a la Carta de 1925, y la posición minoritaria del gobierno en el Congreso Nacional. Las pocas leyes delegatorias aprobadas en esta etapa, se dirigieron a la reorganización de servicios públicos con encargos legislativos, por lo general, acotados ${ }^{68}$. En total, se dictaron 66 DFL, que en su mayor parte reorganizan y fijan plantas, refunden impuestos y crean tributos ${ }^{69}$.

\subsection{PeríOdo 1973-1980}

En este período se dictan un total de $151 \mathrm{DFL}^{70}$. El contexto autoritario de estos años tiene como aspectos relevantes la asunción del Poder Ejecutivo por la Junta de Gobierno militar, la concentración en la misma de las potestades legislativa y constituyente, y la paulatina regulación de las instituciones de gobierno y del proceso legislativo ${ }^{71}$. La concentración de poder en la Junta de Gobierno y su potestad fáctica para dictar decretos leyes no hizo desaparecer la delegación de la potestad legislativa. Su uso puede atribuirse a prácticas administrativas precedentes y perdurantes en la administración del Estado y a dudas acerca de la pertenencia de determinadas materias al ámbito reglamentario o al de la ley ${ }^{72}$. Fue la

65 Con todo, Patricio Aylwin en el debate previo a la reforma constitucional de 1970 destacó que la eliminación de los DFL dejaría sin regulación el régimen de vivienda, el código sanitario, las sociedades anónimas, las compañías de seguros, los servicios eléctricos, entre otras. Cordero (2010) p. 60.

${ }^{66}$ Sobre Banco Central, Ley General de Bancos, Banco del Estado, Servicio de Correos y Telégrafos, Ferrocarriles del Estado.

${ }^{67}$ Silva Bascuñán (1963) p. 163.

68 Por ejemplo, el art. 30 de la Ley No 17.940, de 6 de junio de 1973, autoriza modificar las plantas de la Dirección de Aprovisionamiento del Estado, la Oficina de Planificación Nacional y la Junta Aeronáutica Civil y crear plantas de servicios menores en estos servicios.

69 Según la base de datos de la BCN. La base de datos de la CGR registra 132. Se crean impuestos a los fósforos, a la cerveza, a neumáticos nacionales, al vino, a las bebidas alcohólicas y aguas minerales y mineralizadas.

70 FonCEA (2018) p. 24. El número total no es conocido, pues existen DFL secretos, reservados o de publicación restringida.

71 Ver los decretos leyes núm. 1/73, 9/73, 128/74, 527/74, 788/74 y 991/76.

72 En algunos casos, el propio legislador delegado utiliza la expresión reglamento en su denominación. Así, el art. $1^{\circ}$ del DFL 1-3.063 señala que "[e]l presente reglamento contiene las normas generales por las cuales se regirá la inversión de los recursos del Fondo Común Municipal (...)”; el DFL 10-2.345, en su art. 10 "[a]prueba el siguiente Reglamento de Remates Aduaneros"; el DFL 1.046, dispone en su art. 12 "[l]as disposiciones de 
Contraloría la que en el trámite de toma de razón advirtió inconsistencias en la denominación $\mathrm{dada}^{73}$.

En la mayor parte de los casos, los DFL se utilizaron para regular la reorganización de distintos organismos de la administración del Estado, en especial, para fijar sus plantas, dotación de personal y remuneraciones. Destacan en esta materia algunos sectores como Salud con 35 DFL, Agricultura y Hacienda (que incluye la Superintendencia de Bancos e Instituciones Financieras, Servicio Nacional de Aduanas, Servicio de Impuestos Internos y Dirección de Presupuestos) ${ }^{74}$. Más de un tercio del total de DFL de este período tienen contenido presupuestario explícito.

La técnica delegatoria empleada fue, como siempre, amplia. La ausencia de control, sumada a la potestad constituyente otorgada a la Junta de Gobierno hizo por completo inviable cuestionar la delegación en materias que afectaban derechos constitucionales (como por ejemplo, el tributario $)^{75}$.

\section{EL ÁMBITO DE LA LEY Y LA DELEGACIÓN LEGISLATIVA EN EL RÉGIMEN DE LA CONSTITUCIÓN DE 1980}

La Constitución de 1980 innova en la configuración del ámbito de la ley, como también en los términos utilizados para configurar las materias de ley. En lo que dice relación con el ámbito de la ley, la Carta de 1980, siguiendo la Constitución de la V República francesa, crea un dominio máximo legal, esto es, un listado taxativo de materias susceptibles de regulación legal. Fuera de este dominio, se ejerce la potestad reglamentaria autónoma del Presidente de la República.

Esta innovación puede asociarse a la crítica que desde los años treinta formulaba el Poder Ejecutivo al Congreso Nacional: las leyes penetran en el campo de la potestad reglamentaria ${ }^{76}$. Con el dominio máximo legal se pretendió, como en la constitución gaullista,

este Reglamento (...)”; y el DFL 262/77, señala en su art. 13 "[1] as normas sobre viáticos (...) establecidas en este Reglamento (...)". FonCEA (2018) pp. 33, 34.

73 En el primer DFL (1383/75), que fija el Estatuto del Personal de la Superintendencia de Bancos e Instituciones Financieras, la Contraloría da curso a un acto sometido a toma de razón como decreto supremo señalando que se ajusta a Derecho, pero que ha sido dictado en virtud de una delegación de la potestad legislativa. Lo mismo sucede con el DFL 26/76 del Ministerio de Minería y el 1108/77 del Ministerio de Hacienda. FONCEA (2018) pp. 26 y 27.

74 Foncea (2018) p. 30.

75 La Carta de 1925, después de la reforma de 1970, aceptaba la delegación en lo relativo "al modo de usar, gozar y disponer de la propiedad y a sus limitaciones y obligaciones (...)” (art. 15, No 15). La Constitución de 1980 impide la delegación para la creación de tributos (SSTC 718/07, 759/07 y 773/07).

76 Ver el Mensaje del Presidente de la República en CÁmara de Diputados (1964) 1160. En un informe de comisiones del Senado de 1953 se decía “(...) no es conveniente que el legislador se introduzca en el campo de la potestad reglamentaria y si queremos ser sinceros debemos reconocer que este ha sido un vicio o defecto frecuente en la legislación de los últimos años”. SiLva BASCuñán (1963) p. 164. 
limitar el poder de las mayorías parlamentarias de intervenir en todos los asuntos de su interés (los que en el pasado incluían decisiones particulares de administración) ${ }^{77}$.

Con todo, la forma en que se describen las materias de ley limita las consecuencias del cambio anterior. Es decir, la manera en que el constituyente establece las materias reservadas a la ley genera campos abiertos a la interpretación de la mayoría parlamentaria y, por lo mismo, relativiza el sentido restrictivo del dominio máximo legal. En este sentido, dos numerales del art. 63 de la Constitución son de especial relevancia, el 3 y el $20^{78}$. Cabe agregar que el campo de la ley también se extiende con la protección de los derechos fundamentales reconocidos por la Constitución, la que se encuentra directamente asociada a una reserva legal que crece junto con una tutela que se expande.

A los cambios en el diseño general y determinación del ámbito de la ley, se suman los referidos al control de legalidad y constitucionalidad, la creación de un conjunto de categorías de leyes de quórum especial y, por supuesto, modificaciones en la regulación de la delegación legislativa. En la práctica, ellos no introducen una variación significativa en lo que ha sido el ejercicio de la potestad delegada a partir de 1990.

En cuanto a los mecanismos de control, la labor de la Contraloría General de la República en materia de decretos con fuerza de ley es regulada de un modo más completo por el constituyente. Asimismo, pensando en la posibilidad de simples decretos que, ante la ausencia de delegación, invadan el campo de la ley, es claro que las facultades de control de legalidad y constitucionalidad son más robustas. Las facultades de control del Tribunal Constitucional, en especial después de la reforma del año 2005, permiten una efectiva tutela del campo de la ley y del ejercicio de potestades legislativas delegadas.

Por otro lado, la creación de las LIC, LOC y LQC tiene un efecto restrictivo sobre el ámbito de la ley que puede ser objeto de delegación de la potestad legislativa. No se trata de un cambio importante toda vez que las materias involucradas no atañen a las que han sido, en la historia, objeto de delegación. Mención especial merece, la ley orgánica constitucional sobre organización básica de la Administración Pública, la que por su especial enunciado de "bases" mantiene una generalidad compatible con la práctica de la delegación.

\subsection{El ejercicio de la potestad legislativa delegada en el RÉgimen CONSTitu- CIONAL DE 1980}

Este ejercicio debe dividirse en dos períodos: entre el 11 de marzo de 1981 y el 11 de marzo de 1990, y entre el 12 de marzo de 1990 y el 11 de marzo de 2014, fecha esta última fijada como límite de este trabajo.

\footnotetext{
77 Según Tagle entre 1926 y 1973 se dictaron 13.962 leyes, de las cuales un 51,49\% son leyes de carácter individual, un $39,48 \%$ particulares o dirigidas a un grupo o sector particular, y solo un $8,51 \%$ pueden calificarse de generales; Soto (2015) p. 100; Bronfman (2013) p. 168.

78 Puede sumarse también el número 60 del art. 65, normas que “incidan” en la seguridad social.
} 


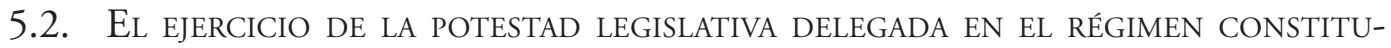
CIONAL DE 1980: PERÍODO 1981-1990

En este período, la CPR recibe una aplicación parcial. La disposición transitoria 21응 declaró la vigencia inmediata del art. 61, referido a la delegación de la potestad legislativa, reemplazando al Congreso Nacional por la Junta de Gobierno. Notemos que a la ausencia de autoridades democráticas se suma cierta concentración de poder legislativo en el Presidente de la República ${ }^{79}$.

En total, entre el 11 de marzo de 1981 y el 11 de marzo de 1990 se dictaron 855 $\mathrm{DFL}^{80}$. De este número, hay una importante concentración en dos años, 1981 y 1982, asociada a decretos destinados a la fijación de plantas municipales ${ }^{81}$. En cuanto a las materias, solo 12 se destinan a textos refundidos y más de 600 regulan remuneración y personal. Como en otros períodos de nuestra historia, el empleo de las potestades delegadas se dirige a un conjunto de reformas en la organización de la administración pública en distintas áreas: municipios, educación, salud y previsión.

En el balance del ejercicio de la potestad legislativa delegada en este período, hay preponderancia de la regulación sobre la propia administración estatal, en particular, para fijar plantas permanentes y remuneraciones. Como es usual pocas leyes delegatorias autorizaron un número significativo de $\mathrm{DFL}^{82}$.

El control constitucional en el período es débil y no es ejercido, pese a que hay varios decretos con fuerza de ley que podrían ser cuestionados en su compatibilidad con la $\mathrm{CPR}$, pues abordan materias que no pueden ser delegadas. Además, subsisten dudas en la utilización de potestad legislativa en materias que podrían ser reguladas mediante el ejercicio de la potestad reglamentaria de ejecución.

\subsection{El EJERCiCiO DE LA POTESTAD LEGISLATIVA DELEGAdA EN EL RÉGIMEN CONSTITU- CIONAL DE 1980: PERÍODO 1990-2014}

Entre el 12 de marzo de 1990 y el 11 de marzo de 2014 se dictan un total de 1113 decretos con fuerza de ley. Se observa una gran oscilación en su número anual, concentración en algunos ministerios, y variaciones importantes entre distintos períodos presidenciales. El año 1994 se aprobaron 341 decretos con fuerza de ley (lo que equivale a más de un tercio de todo el período) y en 1990 un total de 202. Solo en estos dos años se dictan más DFL que leyes y en buena medida estas cifras se explican por la reforma de las plantas de funcionarios municipales ${ }^{83}$. Otra materia importante en lo cuantitativo es la reorganización del sistema de salud, que justifica 240 DFL del Ministerio de Salud que crean o modifican

\footnotetext{
79 El Comandante en Jefe del Ejército -y Presidente durante el período de transición- podía reemplazar en cualquier momento al Oficial General de Armas del Ejército que participaba en la Junta de Gobierno en representación.

80 FONCEA (2018) p. 38. El número es aproximado ya que existen DFL secretos o reservados. Asimismo, hay DFL que en las bases de datos también se encuentran registrados como DS.

81 Más de 80\% del total, 696 DFL. Solo en el año 1981 se aprueban 343 DFL de estos decretos, autorizados por el art. 27 del DL 3.551/81, facultad prorrogada por el art. 23 de la Ley No 18.073. FonCEA (2018) p. 41.

$82 \mathrm{El}$ art. 27 del DL 3.551/81 funda, prórroga incluida, 605 decretos con fuerza de ley. FonCEA (2018) p. 46.

${ }^{83}$ La Ley No 19.280 impulsa 335 decretos con fuerza de ley dirigidos a la reforma de las plantas municipales.
} 
cargos, aunque estos decretos se dictan de forma más espaciada en el tiempo. Un porcentaje pequeño, el $3 \%$ se destina a textos refundidos ${ }^{84}$.

El contraste de estos datos con los períodos presidenciales arroja diferencias notables. En promedio, por año, el número de decretos con fuerza de ley dictados por cada presidente decae entre 1990 y 2014: Patricio Aylwin dicta 87,5; Eduardo Frei, 67,5; Ricardo Lagos, 31,33; Michelle Bachelet, en su primer período, 32,75; y Sebastián Piñera, también en su primer mandato, solo $9,5^{85}$. Por cierto que este dato podría relacionarse con la presencia de mayorías de gobierno en cada cámara y con la cohesión de las respectivas bancadas, pero los ciclos económicos, políticas de expansión o contracción del gasto público, y el contexto que ofrecen las relaciones entre el Congreso Nacional y el Presidente de la República en materia presupuestaria ofrecen una mejor explicación. En este sentido, la Ley de Presupuestos crece en el detalle de la regulación del porcentaje de gastos en personal bajo las categorías de contrata y honorarios. Esta regulación revela el interés parlamentario de incrementar el control sobre el Poder Ejecutivo en esta materia y, por la misma razón, el propósito de acotar la posibilidad de introducir cambios en la planta funcionarial vía legislación delegada.

\section{CONCLUSIONES}

La delegación de la potestad legislativa nace en 1837 y renace en 1927 como una respuesta a necesidades políticas y normativas que se estiman urgentes. Este nacimiento cuenta con el apoyo de una mayoría parlamentaria que justifica su legitimidad en argumentos prácticos y que ejerce influencia y poder sobre los órganos que podrían controlar o rechazar dicha delegación. Los argumentos jurídicos contrarios a su existencia no fueron suficientes para dañar o menoscabar su vigencia y su tardía incorporación a la Constitución, en 1970, acabó con la crítica a su utilización.

En su funcionamiento a lo largo del período estudiado comprobamos el predominio de una técnica de autorización que, en términos más bien amplios, permite al Presidente aprobar normas generales cuyos contenidos están o podrían estar reservados a la ley. No opera la delegación de la potestad legislativa, entendida como un encargo particular sobre una materia que, por algún motivo, el Congreso nacional no quiere regular por medio del procedimiento ordinario.

La precariedad del soporte constitucional de la delegación desde su nacimiento hasta 1970, sumada al constante propósito de la mayoría parlamentaria de no renunciar al poder político asociado al ejercicio de la potestad legislativa, tienden a que la delegación solo se acepte en materias propias de la organización interna del Poder Ejecutivo, las que tanto por su dificultad técnica intrínseca, como por los intereses políticos concernidos, no son fáciles de reformar desde el procedimiento legislativo ordinario. De ahí que la mayor parte de los DFL contengan normas sobre plantas, escalafones, remuneraciones y orgánica de la Administración Pública.

\footnotetext{
8438 DFL. NúNEZ (2015) p. 23.

${ }^{85}$ NúNEZ (2015) p. 28.
} 
El uso de los DFL en este tipo de materias se asienta como práctica generalizada, aun después de la reforma constitucional de 1970 y la regulación de la Carta de 1980. Lo anterior pese a que, de modo explícito, ellas abren la delegación a todo tipo de materias, permitiendo al Congreso fijar las limitaciones, restricciones y formalidades que estime pertinentes en cada caso. Observemos que el anteproyecto del Consejo de Estado, antes mencionado, intentó recoger la experiencia acumulada, circunscribiendo la delegación a un listado de materias acorde con la funcionalidad histórica de la misma, idea que no fue acogida por la Junta de Gobierno.

La utilización de los DFL en materias propias de la administración del Estado, si bien tiene cierto fundamento en la potestad normativa que corresponde a cada poder en sus asuntos propios, colisiona con decisiones que sin duda están en el centro de los checks and balances, como la referida al control sobre el gasto público. En este tópico, observemos que el Congreso Nacional conserva y ejerce, desde 1927 y hasta la fecha, su poder de decisión sobre el total del gasto público comprometido, lo que incluye la posibilidad de imponer restricciones sobre los costos de las disposiciones de reorganización adoptadas. Este control, asociado a los factores antes comentados, desincentiva innovar en la materia, pues lo que se entiende como principal potestad política de los diputados y senadores en esta materia, no sufre merma. Sin embargo, hay merma. En lo particular, aunque no es tema de este trabajo, parece que el mecanismo autorizativo comentado no ha estimulado la construcción de un régimen orgánico y laboral aplicable a todos funcionarios públicos, que avance en la armonización de los intereses que convergen en la materia.

En lo general, la delegación de la potestad legislativa no se ha desarrollado como un instrumento de colaboración entre las mayorías parlamentarias y el Presidente de la República. Aunque hay ejemplos de negociaciones directas entre diputados y senadores y el Presidente fuera del hemiciclo ( $\mathrm{y}$ de las comisiones), para permitir la aprobación expedita de determinados proyectos de ley (v. gr. las recurrentes leyes conocidas como "cortas"), no se ha utilizado el mecanismo delegatorio previsto en la Constitución, con toda la variedad de condiciones que podría imponer el Congreso para el mismo fin. Cabe preguntarse, entonces, si la delegación legislativa no podría transformarse, en el futuro, en un instrumento de colaboración eficiente entre las mayorías parlamentarias y el Presidente para la generación de normas que gocen de respaldo democrático y representativo.

\section{BIBLIOGRAFÍA CITADA}

Andrade Geywitz, Carlos (1971): Elementos de Derecho Constitucional Chileno (Santiago de Chile, Editorial Jurídica de Chile, 2a edición).

Bagehot, Walter (1966): The English Constitution (Ithaca, Cornell University Press).

Barros Arana, Diego (2005): Historia General de Chile, t. XV (Santiago, Editorial Universitaria, 2a edición).

Bernaschina González, Mario (1958): Manual de Derecho Constitucional, t. II (Santiago, Editorial Jurídica de Chile, $3^{\text {a }}$ edición).

Bravo Lira, Bernardino (1996): Por la razón o la fuerza. El Estado de Derecho en la Historia de Chile (Santiago, Ediciones Universidad Católica de Chile). 
Bravo Lira, Bernardino (1992-1993): "El primer constitucionalismo en Chile", Revista de Estudios Histórico-Jurídicos, $\mathrm{N}^{\circ} \mathrm{XV}$ : pp. 303-331.

Bravo Lira, Bernardino (1983): "Los comienzos de la codificación en Chile: la codificación procesal”, Revista Chilena de Historia del Derecho, No 9: pp. 191-210.

Bronfman Vargas, Alan (2017): "Génesis de la delegación legislativa en Chile", Revista de Estudios Histórico-Jurídicos, N XXXIX: pp. 269-297.

Bronfman Vargas, Alan; Cordero Q., Eduardo y Aldunate L., Eduardo (2013): Derecho parlamentario chileno. Funciones y atribuciones del Congreso Nacional (Santiago, LegalPublishing-Thomson Reuters).

Carey, John M. y Shugart, Matthew Soberg (1998): "Calling out the tanks or filling out the forms”, en Carey, John M. y Shugart, Matthew Soberg, Executive Decree Authority (Cambridge, Cambridge University Press), pp. 1-29.

Carrasco Albano, Manuel (1874): La Constitución Política de 1833 (Santiago, Imprenta de la Librería del Mercurio).

Carrasco Delgado, Sergio (2002): Génesis y vigencia de los textos constitucionales chilenos (Santiago, Editorial Jurídica de Chile, $3^{a}$ edición actualizada).

Claro Solar, Luis (1898): Explicaciones de Derecho Civil chileno y comparado. De las personas, t. I (Santiago de Chile, Establecimiento Poligráfico Roma).

Collier, Simon (1977): Ideas y politica de la independencia chilena (trad. Carmen Cienfuegos, Santiago, Editorial Andrés Bello).

Cordero Quinzacara, Eduardo (2010): "La legislación delegada en el derecho chileno y su función constitucional”, Estudios Constitucionales, Vol. 8, № 2: pp. 49-86.

Edwards Vives, Alberto (1972): La organización política de Chile (Santiago de Chile, Editorial del Pacífico S.A., $3^{a}$ edición).

Edwards Vives, Alberto (1959): La fronda aristocrática (Santiago, Editorial del Pacífico S.A.).

Estévez Gazmuri, Carlos (1949): Elementos de Derecho Constitucional Chileno (Santiago, Editorial Jurídica de Chile).

Evans de la Cuadra, Enrique (1970): “La delegación de facultades legislativas", en Frei, Eduardo; Lagos, Gustavo; Molina, Sergio; Silva, Alejandro; Evans, Enrique, y Cumplido, Francisco, Reforma constitucional 1970 (Santiago, Editorial Jurídica de Chile).

Eyzaguirre, Jaime (1987): Ideario y ruta de la emancipación chilena (Santiago, Editorial Universitaria, $8^{\text {a }}$ edición).

Eyzaguirre, Jaime (1986): Historia de las instituciones políticas y sociales de Chile (Santiago, Editorial Universitaria, 7a edición).

Faúndez, Julio (2011): Democratización, desarrollo y legalidad. Chile, 1831-1973 (trad. Natalia Babarovic, Santiago, Ediciones Universidad Diego Portales).

Foncea Delaunoy, Jonathan (2018): Régimen jurídico de la potestad delegatoria en Chile durante los periodos 1973-1981 y 1981-1990. Una revisión a los DFL del Gobierno Militar, Memoria de Prueba para optar al grado de Licenciado en Ciencias Jurídicas (Valparaíso, Pontificia Universidad Católica de Valparaíso).

Góngora, Mario (1994): Ensayo histórico sobre la noción de estado en Chile en los siglos XIX yXX (Santiago, Editorial Universitaria, 5a edición). 
GuZmán Brito, Alejandro (1988): Portales y el Derecho (Santiago, Editorial Universitaria). Heise GonZÁlez, Julio (1986): Evolución histórica del pensamiento parlamentario en Chile (Santiago, Academia Chilena de Ciencias Sociales-Instituto de Chile).

Huneeus, Jorge (1890): La Constitución ante el Congreso, t. I (Santiago, Imprenta Cervantes). Huneeus, Jorge (1891): La Constitución ante el Congreso, t. II (Santiago, Imprenta Cervantes).

IANCu, Bogdan (2012): Legislative Delegation. The Erosion of Normative Limits in Modern Constitucionalism (Middletown DE, Springer).

Jara Cristi, Manuel (1948): Manual de Derecho Administrativo (Santiago, Editorial Jurídica de Chile).

Lastarria, José Victorino (1906): Derecho Público Constitucional Teórico o Filosófico (Santiago de Chile, Imprenta Barcelona).

Letelier, Valentín (1917): Génesis del Estado y de sus instituciones fundamentales. Introducción al estudio del Derecho Público (Buenos Aires, Cabaut y Cía. Editores).

Letelier, Valentín (1887): Sesiones de los Cuerpos Lejislativos de la República de Chile, t. I (Santiago, Imprenta Cervantes)

Locke, John (1769): Two Treatises of Government (London, A. Millar y otros, 6a reimpresión). Loughlin, Martin (2012): Foundations of Public Law (Oxford, Oxford University Press).

Mayer, Otto (1949): Derecho Administrativo Alemán, t. I, (trad. H. Heredia y E. Krotoschin de la versión francesa de 1903, Buenos Aires, Depalma).

Montesquieu, Charles Louis de Secondat (1998): Del Espíritu de las Leyes (trad. Mercedes Blázquez y Pedro de Vega, Madrid, Tecnos, 4a edición).

Núnez Ramírez, Fernanda (2015): Taxonomía de la legislación delegada en Chile en el período 1990-2014, Memoria de Prueba para optar al grado de Licenciado en Ciencias Jurídicas (Valparaíso, Pontificia Universidad Católica de Valparaíso).

Obando Camino, Iván (2014): "Algunas notas sobre el proceso de institucionalización de las comisiones parlamentarias chilenas (1828-1973)", en Núñez Poblete, Manuel, La Internacionalización del Derecho Público (Santiago, Thomson Reuters - La Ley Pontificia Universidad Católica de Valparaíso), pp. 627-646.

Pereira Menaut, Antonio-Carlos y Pereira Sáez, Carolina (2015): Teoría Política (Santiago de Compostela, Andavira).

Pereira Menaut, Antonio-Carlos (1992): El ejemplo constitucional de Inglaterra (Madrid, Servicio de Publicaciones Facultad de Derecho Universidad Complutense de Madrid).

Roldán, Alcibiades (1917): Elementos de Derecho Constitucional de Chile (Santiago, Imprenta Barcelona).

Silva Bascuñán, Alejandro (1963): Tratado de Derecho Constitucional, t. III (Santiago, Editorial Jurídica de Chile).

Silva Cimma, Enrique (2008): "El Tribunal Constitucional de Chile (1971-1973)", Cuadernos del Tribunal Constitucional, $\mathrm{N}^{\circ} 38$ (Santiago, Tribunal Constitucional).

Soto Velasco, Sebastián (2015): Congreso Nacional y proceso legislativo. Teoría y práctica (Santiago, Thomson Reuters).

Urzúa Valenzuela, Germán (1970): Evolución de la Administración Pública chilena (18181968) (Santiago, Editorial Jurídica de Chile). 
Urzúa Valenzuela, Germán y García Barzelatto, Ana María (1971): Diagnóstico de la burocracia chilena (1818-1969) (Santiago, Editorial Jurídica de Chile).

Urzúa Valenzuela, Germán (1992): Historia politica de Chile y su evolución electoral (Santiago, Editorial Jurídica de Chile).

Valencia Avaria, Luis (1986): Anales de la República (Santiago, Andrés Bello).

Villalobos R., Sergio (2005): Portales. Una falsificación histórica (Santiago, Editorial Universitaria, $4^{\mathrm{a}}$ edición).

\section{JURISPRUDENCIA CITADA}

STC 5/72, de 5 de abril de 1972.

STC 511/06, de 27 de junio de 2006.

STC 718/07, de 26 de noviembre de 2007.

STC 759/07, de 26 de noviembre de 2007.

STC 773/07, de 26 de noviembre de 2007

STC 1191/08, de 19 de mayo de 2009.

\section{NORMAS CITADAS}

Constitución Política de la República (25/5/1833).

Constitución Política del Estado (18/9/1925).

Constitución Política de la República (21/10/1980).

DFL 1383/75 (29/11/75), Fija estatuto del personal de la Superintendencia de Bancos e Instituciones Financieras.

DFL 26/76 (4/6/77), Estatuto del personal de la Comisión Chilena del Cobre.

DFL 1108/77 (6/1/78), Modifica escalafón de los Jefes Superiores de Servicios del DFL $90 / 77$.

DFL 1-3063 (13/6/80), Reglamenta aplicación del inc. 2º del art. 38 del DL 3.063 de 1979.

DFL 10-2345 (5/9/79), Aprueba Reglamento de Remates Aduaneros.

DFL 1-046/79 (20/12/77), Reglamenta regímenes de trabajos extraordinarios.

DFL 262/77 (3/5/77), Aprueba el Reglamento de viáticos para el personal de la Administración Pública.

DL 3551/81 (2/1/81), Fija normas sobre remuneraciones y sobre personal para el sector público.

LEY del 31 de enero de 1837.

Ley No 4113 (25/1/1927), Modifica Decreto Ley No 755, de 1925 y otorga facultades extraordinarias al Ejecutivo para reorganizar finanzas.

LeY No 4795 (22/2/1930), Autoriza al Presidente de la República para dictar el estatuto administrativo, disposiciones para la aplicación de la ley de reclutas y reemplazos y tome las medidas necesarias, a fin de incorporar al régimen político y administrativo del país, el departamento de Arica.

Ley No 4945 (6/2/1931). 
Bronfman VArgas, Alan — "El ejercicio de la potestad legislativa delegada al Presidente de la República ..."

LEY No 17.940 (6/6/1973), Concede mensualmente un anticipo de reajuste a todos los trabajadores y modifica las leyes que indica.

Ley No 18.073 (1/12/1982), Ley de Presupuesto para el año 1982.

LeY No 19.280 (16/12/1993), Modifica Ley N¹8.695, orgánica constitucional de municipalidades, y establece normas sobre plantas de personal de las municipalidades.

\section{OTRAS FUENTES}

Boletín de la leyes y de las órdenes y decretos (1841) (2a ed., Santiago de Chile, Imprenta de la Independencia,), tomos VII, VIII.

Cámara de Diputados (1964): Boletín de Sesiones de la Cámara de Diputados, Legislatura ordinaria.

Comisión de Estudios para la Nueva Constitución (1974): Sesión 22, en www.leychile.cl/ Consulta/antecedentes_const_1980. Fecha de consulta: 30 de julio de 2018.

Consejo de Estado (1979): Sesión 88 y Sesión 89, en www.leychile.cl/Consulta/antecedentes_const_1980. Fecha de consulta: 30 de julio de 2018.

Diario Oficial y Contraloría General de la República (2010): Leyes de la República de Chile 1810-2010 (Santiago, Diario Oficial).

Sesiones de los Cuerpos legislativos de la República de Chile (1887): 1811 a 1848, Congreso Nacional de 1811, Senados de 1812 y 1814 (Santiago, Imprenta Cervantes).

Subcomisión de Reformas Constitucionales (1925): Actas (Santiago, Imprenta Universitaria). 